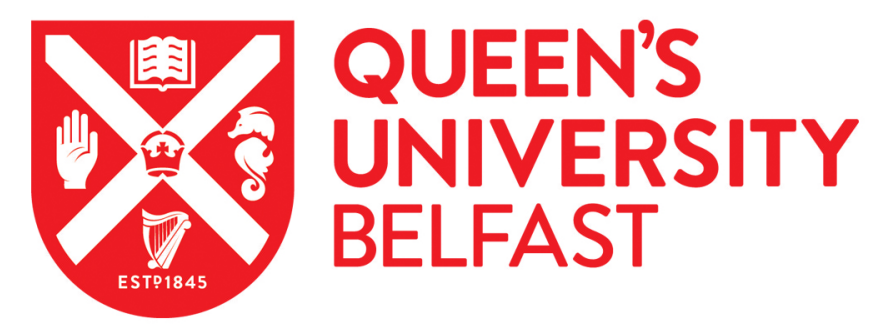

\title{
Building pH Sensors into Paper-based Small-molecular Logic Sys- tems for Very Simple Detection of Edges of Objects
}

Ling, J., Naren, G., Kelly, J., Moody, T. S., \& de Silva, A. P. (2015). Building pH Sensors into Paper-based Small-molecular Logic Sys-tems for Very Simple Detection of Edges of Objects. Journal of the American Chemical Society, 137(11), 3763-3766. https://doi.org/10.1021/jacs.5b00665

Published in:

Journal of the American Chemical Society

Document Version:

Peer reviewed version

Queen's University Belfast - Research Portal:

Link to publication record in Queen's University Belfast Research Portal

Publisher rights

Copyright (C) 2015 American Chemical Society

This document is the Accepted Manuscript version of a Published Work that appeared in final form in Journal of the American Chemical Society, copyright $\odot$ American Chemical Society after peer review and technical editing by the publisher.

To access the final edited and published work see: http://pubs.acs.org/doi/abs/10.1021/jacs.5b00665

\section{General rights}

Copyright for the publications made accessible via the Queen's University Belfast Research Portal is retained by the author(s) and / or other copyright owners and it is a condition of accessing these publications that users recognise and abide by the legal requirements associated with these rights.

\section{Take down policy}

The Research Portal is Queen's institutional repository that provides access to Queen's research output. Every effort has been made to ensure that content in the Research Portal does not infringe any person's rights, or applicable UK laws. If you discover content in the Research Portal that you believe breaches copyright or violates any law, please contact openaccess@qub.ac.uk. 


\title{
Building pH Sensors into Paper-based Small-molecular Logic Sys- tems for Very Simple Detection of Edges of Objects
}

\author{
Jue Ling, Gaowa Naren, Jessica Kelly, Thomas S. Moody and A. Prasanna de Silva \\ School of Chemistry and Chemical Engineering, Queen's University, Belfast BT9 5AG, Northern Ireland.
}

\section{Supporting Information Placeholder}

\begin{abstract}
Genetically-engineered bacteria and reactive DNA networks detect edges of objects, as done in our retinas and as also found within computer vision. We now demonstrate that simple molecular logic systems (a combination of a pH sensor, a photo acid generator and a $\mathrm{pH}$ buffer spread on paper) without any organization can achieve this relatively complex computational goal with good-fidelity. This causes a jump in the complexity achievable by molecular logic-based computation and extends its applicability. The molecular species involved in light dose-driven 'off-on-off' fluorescence is diverted in the 'on' state by proton diffusion from irradiated to unirradiated regions where it escapes a strong quencher, thus visualizing the edge of a mask.
\end{abstract}

$\mathrm{pH}$ sensors ${ }^{1,2}$ have served as starting points of approaches such as molecular logic, ${ }^{3}$ indicator displacement assays, ${ }^{4}$ emulation of photosynthetic reaction centres, ${ }^{5,6}$ and molecular versions of glass pH electrodes. ${ }^{7}$ We now use $\mathrm{pH}$ sensors to lift the field of molecular logic-based computation ${ }^{8-13}$ to a much higher plane by demonstrating human-level computing by small molecules. Important advances in the level of complexity of molecular logic have been achieved by using chemical species to link gates, ${ }^{14-17}$ by employing multi-component photochromics, ${ }^{18,19}$ by using cuvet arrays, ${ }^{20,21}$ and by the use of algorithmic pipeting protocols in multiwell plates. ${ }^{22}$

We present the first instance of small synthetic molecules performing a major computation that humans do often during each waking hour. Parallel processing by small molecular logic systems $^{8-13}$ simply detects edges with good-fidelity on low-cost paper substrates. ${ }^{23,24}$ Edge detection means the visualization of a boundary between dark and light regions while suppressing the visualization of the regions themselves. Edge detection is crucial in animal $^{25}$ and computer ${ }^{26}$ vision for survival and security/automation. While this can be achieved by reactive DNA networks ${ }^{27}$ which are reminiscent of life-processes and by bacteria, ${ }^{28,29}$ small synthetic molecules (with no such connection to life) performing computations which are deep-seated in human nature are remarkable. Other previous attempts required external data processing. ${ }^{30}$

Previously, small molecules could only carry out small-scale integrated logic operations by themselves. Since our presentation of molecular logic systems, ${ }^{3}$ Boolean ideas have been applied in molecular biology, cell physiology and genetics. ${ }^{31-37} \mathrm{~A}$ known $\mathrm{pH}$ sensor molecule ${ }^{38}$ displays 'off-on-off' fluorescence (with binary XOR and ternary logic aspects ${ }^{8}$ ) when driven by light dose as the input, once combined with a photo acid generator. ${ }^{39}$ This combination is applied to a moist field of basic pH buffer (absorbed on

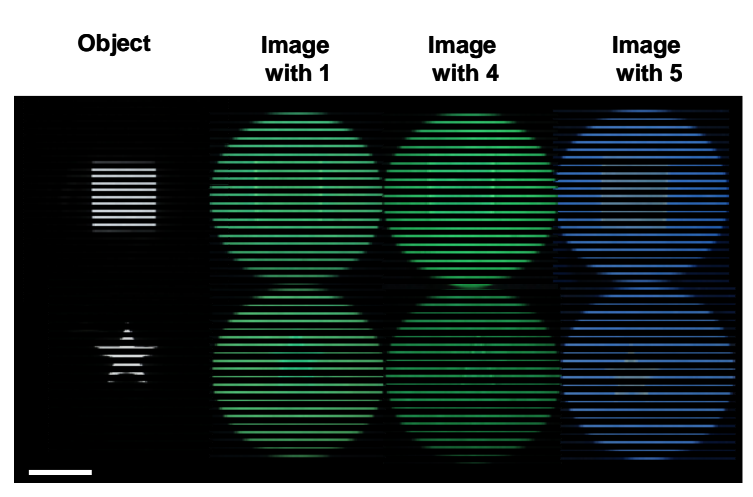

FIGURE 1. Photographs of objects and fluorescent images. The object is a hole cut in an opaque, rigid mask. The writing 254 nm light shone through the mask onto the substrate for 30,16 and $32 \mathrm{~min}$ for molecular logic systems containing sensor $\mathbf{1}, \mathbf{4}$ and $\mathbf{5}$ respectively. The reading light is $366 \mathrm{~nm}$ for this figure and the next two. Scale bar $=4.0 \mathrm{~cm}$ (see supporting information, section 8).
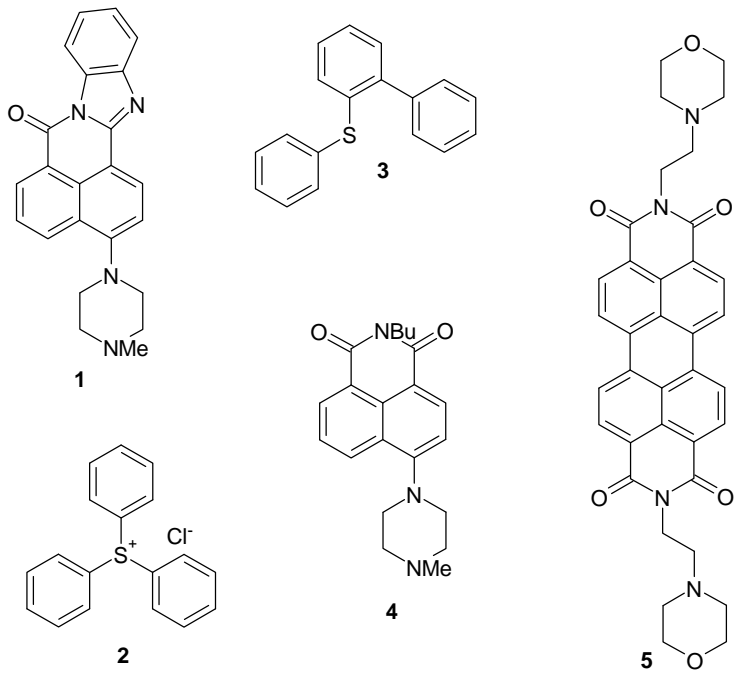

laboratory filter paper) so that the irradiated areas become $\mathrm{pH}$ low while the unirradiated areas stay $\mathrm{pH}$ high. At short exposure times, this produces a bright fluorescent 'positive photograph' of the object. ${ }^{39}$ However at longer times, a photo-product of the photo acid generator serves as quencher so that the irradiated area loses its fluorescence again. ${ }^{40-42}$ Local diffusion of $\mathrm{H}^{+}$past the edge into the unirradiated region causes those sensor molecules to 
light up, visualizing the edge with a resolution of 1-2 mm under our conditions. Further optimization should be possible by sensible variation of each of the components of the molecular logic system. The appeal of this 'light-up and look' protocol is increased by requiring only known molecules and simple inexpensive equipment (a common laboratory uv lamp) for the key experiment.

As vividly seen in Figure 1, objects of two shapes clearly show up their perimeters as continuous fluorescent lines when a prepared paper containing a logical molecular mixture is exposed to $254 \mathrm{~nm}$ uv light through the appropriate mask. The paper substrate is prepared by soaking it in an aqueous methanolic solution $(1: 1, \mathrm{v} / \mathrm{v})$ of $\mathbf{1}\left(10^{-4} \mathrm{M}\right), 2\left(10^{-3} \mathrm{M}\right)$ and $\mathrm{Na}_{2} \mathrm{CO}_{3}\left(10^{-4} \mathrm{M}\right)$ at $\mathrm{pH} 9.2$ and then drying it for 4 minutes at $50 \mathrm{C}$. We have shown that 1 switches 'on' its fluorescence by a factor of 200 when it binds $\mathrm{H}^{+}$, characterized by a $\mathrm{pK}_{\mathrm{a}}$ value of $7.3 .^{38}$ The low fluorescence quantum yield of $\mathbf{1}$ in basic media ( $\mathrm{pH}$ 9.2) occurs by a mechanism resembling photoinduced electron transfer $(\mathrm{PET})^{38}$ known as twisted intramolecular charge transfer (TICT). ${ }^{43}$ We have generalized the principle of fluorescent PET sensing previously. ${ }^{44,45}$ Sensor $\mathbf{4}^{38}$ behaves similarly whereas sensor 5 is a straightforward PET sensor (see supporting information, section 1). The protons required for such switching 'on' of $\mathbf{1}$ are provided in the present case by $254 \mathrm{~nm}$ photolysis of $\mathbf{2}$ which is an established photo acid generator, with 2-(phenylthio)biphenyl (3) as another major photoproduct. ${ }^{46}$ In effect, the weak base $\left(\mathrm{Na}_{2} \mathrm{CO}_{3}\right)$ is titrated with photoproduced $\mathrm{H}^{+}$. During industrial photolithography, 2 is irradiated and then baked to remove volatiles. Under such conditions, fluorescent $\mathrm{pH}$ sensors related to $\mathbf{1}$ combine with $\mathrm{H}^{+}$(produced from 2) in irradiated areas so that open areas of masks are usually imaged as bright regions, i.e. a 'positive photograph' is produced. ${ }^{39}$ Photoinduced colour development from absorptiometric $\mathrm{pH}$ sensors and photo acid generators in hydrogels in non-imaging contexts is also known. ${ }^{47}$ Edge detection was not an issue in these studies.

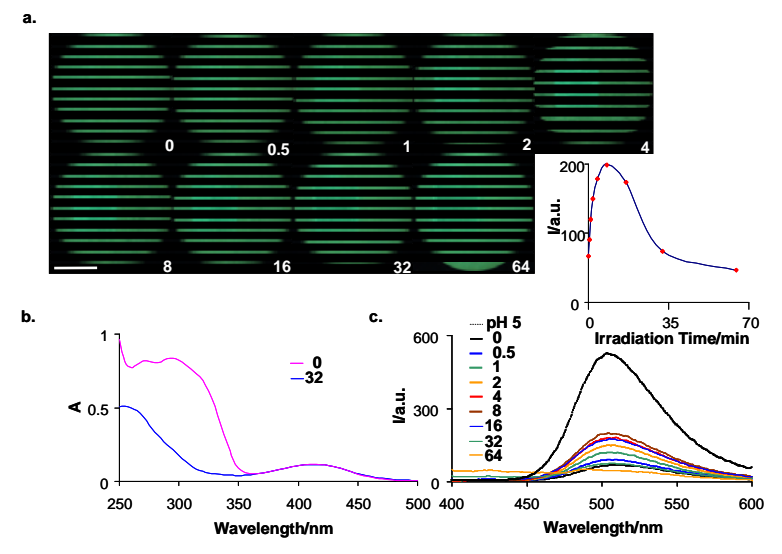

FIGURE 2. a) Photographs of fluorescent images after writing through the 'square' mask onto the substrate, containing the logical molecular solution including $\mathbf{1}$, for varying cumulative times in minutes as noted in each photograph. Scale bar $=4.0 \mathrm{~cm}$. b) $\mathrm{Uv}$ spectra of the extract from the substrate, after writing for 0 and 32 min. c) Fluorescence emission spectra $\left(\lambda_{\text {exc }} 366 \mathrm{~nm}\right)$ of the logical molecular solution including $\mathbf{1}$, while irradiated with $254 \mathrm{~nm}$ light for the stated cumulative times in minutes. Inset: Temporal variation of fluorescence intensity $\left(\lambda_{\text {em }} 504 \mathrm{~nm}\right)$ abstracted from the fluorescence spectra (see supporting information, section 9).

Following our discovery of the fluorescent PET sensing capabilities of the 4 -(aminoalkyl)-aminonaphthalimide system, ${ }^{48}$ it was developed into metal sensing applications by Roche Diagnostics in consultation with us ${ }^{49,50}$ and it was also taken up by many others. ${ }^{39,51-55}$ So it is natural that many of us would continue to exploit the useful properties of this molecular motif: hence, our use of sensors $\mathbf{1}$ and $\mathbf{4}$ in the current work. A simple logic step is insufficient to go from ref. 39 to our paper since the different substrate needs to be controlled in terms of two orthogonal variables (pH and diffusivity) in order to attain a very original goal - that of edge detection. Our experiment uses a pH-buffered and partially dried paper where a optimal level of water is essential, whereas water is virtually absent following the baking protocol of ref. 39 .

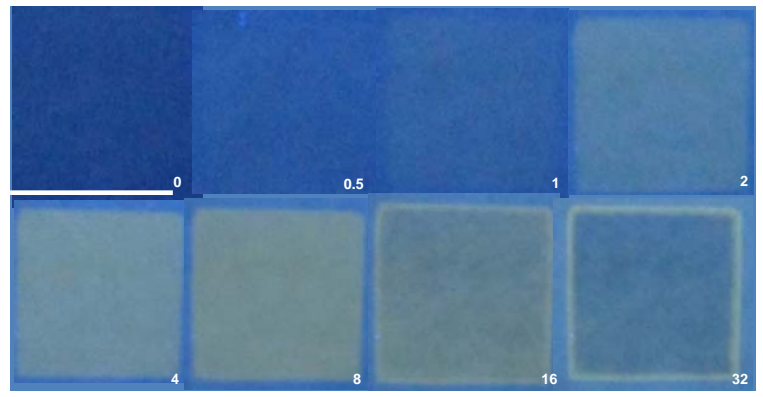

FIGURE 3. Photographs of fluorescent images after writing through the 'square' mask onto the substrate, containing the logical molecular solution including $\mathbf{5}$, for varying cumulative times in minutes as noted in each photograph. Only the zoomed-in sections of the irradiated region and the adjacent areas are shown. Scale bar $=4.0 \mathrm{~cm}$ (see supporting information, section 10 ).

The original result of edge detection arises in our moist paper experiment because we arrange for light dose-driven 'off-on-off' fluorescence behavior in the irradiated regions and because we allow for slow diffusion of $\mathrm{H}^{+}$across the edge from the irradiated to unirradiated regions. The parallel processing done by molecules in irradiated and unirradiated regions completes the edge detection task. We find that $8 \times 10^{15}$ molecules of $\mathbf{1}$ are involved ${ }^{56}$ to generate the edge of the 'square' object in Figure 1b (see supporting information, section 3). 'Off-on-off' fluorescence behavior refers to a fluorescence intensity which switches 'on' and then switches 'off' as the driving input is continuously increased. ${ }^{57}$ 'Off-on-off' fluorescence behavior can be understood as binary XOR logic under some conditions ${ }^{1,2}$ and as a ternary logic type more generally ${ }^{1}$. Light dose-driven 'off-on-off' fluorescence has precedents, ${ }^{40-42}$ but not for application in edge detection. Figure 2c shows this 'off-on-off' behavior in solution for our logical molecular mixture. The origin of the light dose-driven 'off-on' segment was explained in a previous paragraph. The 'on-off' segment occurs by the gradual accumulation of the photoproduct 3 , which causes bimolecular quenching of the fluorescence of protonated $\mathbf{1}$ via PET occurring from $\mathbf{3}$ to $\mathbf{1}$ (Stern-Volmer quenching constant, $\mathrm{Ksv}=110 \mathrm{M}^{-1}$, in methanol). A similar behavior is seen in the irradiated areas of the paper imaging experiment (albeit with smaller fluorescence switching factors): the fluorescence intensity increases initially but then falls back as the writing time is increased (Figures 2a and 3). 2 also causes bimolecular quenching (via PET from 1 to 2 ) of the fluorescence of protonated $\mathbf{1}$ (Ksv = $96 \mathrm{M}^{-1}$, in methanol), but the resulting fluorescence intensities are large enough for easy detection by camera or by naked eye. Figure $2 \mathrm{~b}$ shows that $\mathbf{1}$ is largely preserved during irradiation, whereas $\mathbf{2}$ is significantly decomposed (into $\mathbf{3}$ and $\mathrm{H}^{+}$). ${ }^{46}$

It is worth reiterating that the irradiated areas are understood to show XOR logic using light dose inputs ${ }^{40-42}$ and fluorescence output. On the other hand, no logic assignment can be made in a similar manner to the visualized edges themselves or to the unirradiated areas since the light dose is not supplied directly to those 
places. The overall edge detection process is much more complex than a XOR logic operation and, in the final analysis, corresponds to the Canny algorithm ${ }^{26}$ running on a full computer with a graphical user interface. When the Canny algorithm is run on a picture, pixels are raster-scanned and central differences are taken (meaning the intensity of the pixel ahead minus the intensity of the pixel behind in the horizontal line) after each pixel has been averaged in a Gaussian distribution with intensities in pixels vertically above and below. Then all pixels which display a higher central difference than a chosen threshold are declared as edge pixels. A further check of contiguity is applied so that isolated edge pixels are declared as 'false positive' and rejected.

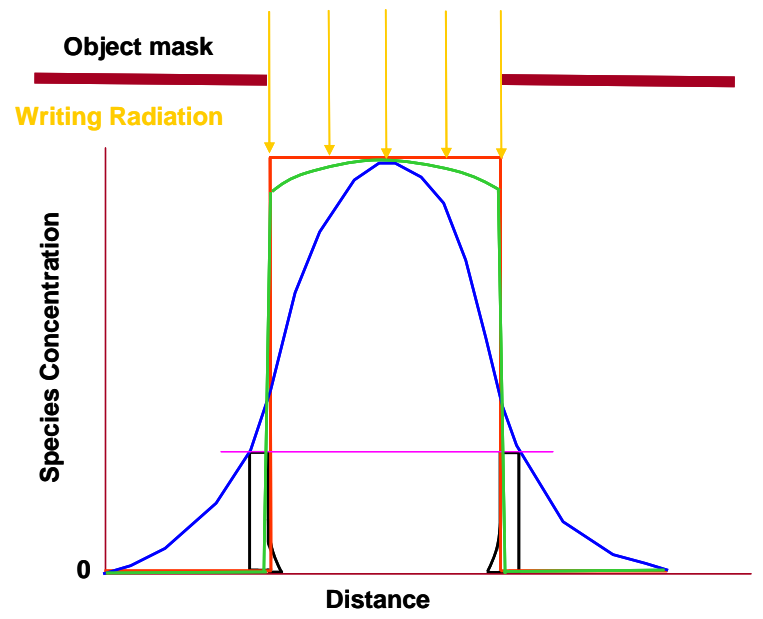

FIGURE 4. Scheme of visible edge development, in terms of concentration - distance profiles: $\mathrm{H}^{+}$at time $=0$ (red), $\mathrm{H}^{+}$at time $=\mathrm{t}$ (blue) and $\mathbf{3}$ at time $=\mathrm{t}$ (green). The two points where the horizontal pink line intersects the blue curve shows where the protons (which have arrived in the locality) have exactly cancelled out the local buffer. The observed edges are shown in black (see supporting information, section 11).

Our imaging experiment is performed on moist paper which is optimally dried for edge visualization so that $\mathrm{H}^{+}$diffuses down a concentration gradient, but at a controlled slow rate owing to limited water. In particular, we avoid fast convective diffusion (see supporting information, section 5). As the photoacid generator photodecomposes, protons accumulate in the irradiated regions and $\mathrm{H}^{+}$gradient is set up at the edges. This permits $\mathrm{H}^{+}$diffusion to the unirradiated areas to switch 'on' the fluorescence of sensor molecules which are resident there. Under our experimental conditions (over time periods of ca. 30 minutes), edges of 1-2 mm are clearly visualized (Figures 1, 2a and 3). The rather sharp front of the edge (towards the unirradiated areas) is due to the extremely non-linear 'switching on' of the sensor fluorescence at the endpoint of the acid-base titration in the locality. ${ }^{1}$ The sharpness of part of the trailing edge is due to the light delivery from the binary object and subsequent production of $\mathbf{3}$. The less sharp part of the trailing edge is caused by weaker bimolecular quenching due to photoproduct 3 , as it slowly diffuses away at this position due to its own concentration gradient (Figure 4). As the experiment progresses, the filter paper dries further, thus stabilizing the visualized edge. Increased writing light intensity (to $6.5 \times 10^{-9}$ from $3.4 \times 10^{-9}$ Einstein $\mathrm{cm}^{-2} \mathrm{~min}^{-1}$ (for a caveat, see supporting information, section 2)) permits reduction of the optimum writing time to $24 \mathrm{~min}$ from $30 \mathrm{~min}$ without losing edge resolution. It is probable that the use of even higher writing intensities will not only reduce the time of the experiment but also sharpen the edge resolution by limiting $\mathrm{H}^{+}$diffusion further.

Contact effects between the mask and the substrate are evaluated by inserting a spacer mask. The edge detection capability is unaffected (see supporting information, section 6), suggesting that contact effects are unimportant.

This approach to molecular logical edge detection is probably general since the detailed experimental results obtained with $\mathbf{1}$ can also be replicated (with minor quantitative differences) with $\mathbf{4}^{38}$ and $\mathbf{5}$, which emit $20 \mathrm{~nm}$ and $42 \mathrm{~nm}$ further to the red respectively (Figure 1 and supporting information, section 1; Figure 3). The availability of electrochemical data for close relatives of $\mathbf{4}$ allows quantitation of the PET processes involving the related structure $\mathbf{1}$ (see supporting information, section 4).

To summarize, an aminoalkyl fluorophore is quenched by nitrogen lone pair participation with an aromatic unit. This leads to $\mathrm{pH}$ sensor ability since fluorescence is enabled upon protonation. A filter paper is treated with an aqueous methanolic solution of the sensor, photoacid generator 2 and a basic buffer $\left(\mathrm{Na}_{2} \mathrm{CO}_{3}\right)$. When the paper is partially dried and exposed to $254 \mathrm{~nm}$ writing light, acid is generated. The fluorescence at time zero is intramolecularly quenched but the photoproduced acid overcomes the carbonate buffer at that locality in the irradiated region so that fluorescence is switched 'on'. Further irradiation causes intermolecular quenching of fluorescence by photoproduct 3 in the irradiated region. Meanwhile, diffusion of protons into the unirradiated area bordering the irradiated area and their overcoming of carbonate at that locality cause the fluorescence of the sensor to be switched 'on' as well. The abrupt nature of fluorescence indication during acid-base titration sharpens the fluorescence front so that the visualized edge is reasonably well-defined. Proton diffusion is slowed by reducing the water content of the filter paper through partial drying. Thus the visualized edge is $1-2 \mathrm{~mm}$ in width. The molecular logic system achieves the rather complex human-level computation of edge detection by itself. To achieve this goal, semiconductor-based computers need to employ a graphical user interface and software such as the Canny Edge Detection algorithm.

In conclusion, parallel processing by small synthetic molecular logic systems on paper substrates directly detects edges of objects, which is a rather complex computational task normally requiring a highly-organized biomolecular system or a substantial 'stored program' computer with a graphical user interface running detailed software, e.g. Canny algorithm. ${ }^{26}$ This represents a considerable advance for small molecular-logic based computation, which though already useful, ${ }^{8,58}$ is rudimentary in nature. The current achievement and the availability of dense molecular memories $^{59,60}$ also demonstrate the considerable informationhandling capabilities of small molecules.

\section{ASSOCIATED CONTENT}

\section{Supporting Information}

Synthesis and characterization of 5. Ferrioxalate actinometry. Estimation of the number of molecules involved in producing the edge of the 'square' object. PET basis of the bimolecular fluorescent quenching processes. Influence of drying on the clarity of edge detection. Elimination of possible contact effects by using a spacer mask. The smallness of the molecules employed in this work. Experimental details pertinent to Figures 1, 2 and 3. Additional information for Figure 4. This material is available free of charge via the Internet at http://pubs.acs.org.

\section{AUTHOR INFORMATION}

\section{Corresponding Author}

E-mail; a.desilva@qub.ac.uk 
Notes

The authors declare no competing financial interests.

\section{ACKNOWLEDGMENT}

We thank X. G. Ling, L. H. Wang, J. Stevenson and D. T. Coulter for support.

\section{REFERENCES}

(1) Indicators, Ed. Bishop, E., Pergamon, Oxford, 1972

(2) Chemosensors, Eds: Wang, B. H.; Anslyn, E. V., Wiley, Hoboken, 2011.

(3) de Silva, A. P.; Gunaratne, H. Q. N.; McCoy, C. P. Nature 1993, 364, 42-44.

(4) Anslyn, E. V. J. Org. Chem. 2007, 72, 687-699.

(5) de Silva, A. P.; Rice, T. E. Chem. Commun. 1999, 163164.

(6) Liu, J. L.; de Silva, A. P. Inorg. Chim. Acta 2012, 381, 243-246.

(7) de Silva, A. P.; de Silva, S. S. K.; Goonesekera, N. C. W.; Gunaratne, H. Q. N.; Lynch, P. L. M.; Nesbitt, K. R.; Patuwathavithana, S. T.; Ramyalal, N. L. D. S. J. Am. Chem. Soc. 2007, 129, 3050-3051.

(8) de Silva, A. P. Molecular Logic-based Computation, Royal Society of Chemistry, Cambridge, 2013

(9) Szacilowski, K., Infochemistry, Wiley-VCH, Chichester, 2012

(10) Molecular and Supramolecular Information Processing, Ed: Katz, E., Wiley-VCH, Weinheim, 2012

(11) Biomolecular Information Processing, Ed: Katz, E., WileyVCH, Weinheim, 2012

(12) Balzani, V.; Venturi, M.; Credi, A., Molecular Devices and Machines, 2nd ed. Wiley-VCH, Weinheim, 2008.

(13) Andréasson, J.; Pischel, U. Chem. Soc. Rev., 2010, 39, 174-188.

(14) Raymo, F. M.; Giordani, S. J. Am. Chem. Soc. 2002, 124, 2004-2007.

(15) Giordani, S.; Cejas, M. A.; Raymo, F. M. Tetrahedron 2004, 60, 10973-10981.

(16) Erbas-Cakmak, S.; Akkaya, E. U. Angew. Chem. Int. Ed. 2013, 52, 11364-11368.

(17) Ecik, E. T.; Atilgan, A.; Guliyev, R.; Uyar, T. B.; Gumusa, A.; Akkaya, E. U. Dalton Trans. 2014, 43, 67-70.

(18) Pischel, U.; Andreasson, J.; Gust, D.; Pais, V. F. ChemPhysChem 2013, 14, 28-46.

(19) Andreasson, J.; Pischel, U.; Straight, S. D.; Moore, T. A.; Moore, A. L.; Gust, D. J. Am. Chem. Soc. 2011, 133, 11641-11648.

(20) Raymo, F. M.; Giordani, S. Proc. Natl. Acad. Sci. U. S. A. 2002, 99, 4941-4944.

(21) Szacilowski, K. Chem. Eur. J. 2004, 10, 2520-2528.

(22) Elstner, M.; Axthelm, J.; Schiller, A. Angew. Chem. Int. Ed. 2014, 53, 7339-7343.

(23) Gong, S.; Schwalb, W.; Wang, Y. W; Chen, Y; Tang, Y; Si, J.; Shirinzadeh, B. Nature Commun. 2014, 5, 3132.

(24) Maxwell, E. J.; Mazzeo, A. D.; Whitesides, G. M. MRS Bull. 2013, 38, 309-314.

(25) How animals see the world, eds. Lazareva, O. F.; Shimizu, T.; Wasserman, E. A., Oxford University Press, Oxford, 2012.

(26) Shapiro, L. G.; Stockman, G. C., Computer Vision, Prentice-Hall, Upper Saddle River, NJ, 2001

(27) Chirieleison, S. M.; Allen, P. B.; Simpson, Z. B.; Ellington, A. D.; Chen, X. Nature Chem. 2013, 5, 1000-1005.

(28) Tabor, J. J.; Salis, H. M.; Simpson, Z. B.; Chevalier, A. A.; Levskaya, A.; Marcotte, E. M.; Voigt, C. A.; Ellington, A. D. Cell 2009, 137, 1272-1281.

(29) Levskaya, A.; Chevalier, A. A.; Simpson, Z. B.; Lavery, L. A.; Levy, M.; Davidson, E. A.; Scouras, A.; Ellington, A. D.; Marcotte, E. M. Nature 2005, 438, 441-442.
(30) Yang, J. H.; Wang, G. Y. Thin Solid Films 1998, 324 281-284.

(31) Stojanovic, M. N.; Stefanovic, D. Nature Biotechnol. 2003, 21, 1069-1074

(32) Istrail, S. ; Davidson, E. H. Proc. Natl. Acad. Sci. USA 2005, 102, 4954-4959.

(33) Rackham, O.; Chin, J. W. J. Am. Chem. Soc. 2005, 127, 17584-17585

(34) Win, M. N.; Smolke, C. D. Science 2008, 322, 456-460.

(35) Friedland, A. E.; Lu, T. K.; Wang, X.; Shi, D.; Church, G.; Collins, J. J. Science 2009, 324, 1199-1202

(36) Pei, R.; Matamoros, E.; Liu, M.; Stefanovic, D. Stojanovic, M. N., Nature Nanotechnol. 2010, 5, 773-777.

(37) Xie, Z.; Wroblewska, L.; Prochazka, L.; Weiss, R. Benenson, Y. Science 2011, 333, 1307-1311.

(38) Zheng, S.; Lynch, P. L. M.; Rice, T. E.; Moody, T. S.; Gunaratne, H. Q. N.; de Silva, A. P. Photochem. Photo biol. Sci. 2012, 11, 1675-1681.

(39) Tian, H.; Gan, J.; Chen, K. C.; He, J.; Song, Q. L.; Hou X. Y. J. Mater. Chem. 2002, 12, 1262-1267.

(40) Pina, F.; Melo, M. J.; Maestri, M.; Passaniti, P.; Balzani, V. J. Am. Chem. Soc. 2000, 122, 4496-4498.

(41) Silvi, S.; Constable, E. C.; Housecroft, C. E.; Beves, J. E. Dunphy, E. L.; Tomasulo, M.; Raymo, F. M.; Credi, A. Chem. Commun. 2009, 1484-1486.

(42) Silvi, S.; Constable, E. C.; Housecroft, C. E.; Beves, J. E Dunphy, E. L.; Tomasulo, M.; Raymo, F. M.; Credi, A. Chem. Eur. J. 2009, 15, 178-185.

(43) Rettig, W. Top. Curr. Chem. 1994, 169, 253-299.

(44) de Silva, A. P.; Gunaratne, H. Q. N.; Gunnlaugsson, T.; Huxley, A. J. M.; McCoy, C. P.; Rademacher J. T.; Rice, T. E. Chem. Rev, 1997, 97, 1515-1566.

(45) de Silva, A. P. J. Phys. Chem. Lett. 2011, 2, 2865-2871.

(46) Dektar, J. L.; Hacker, N. P. J. Am. Chem. Soc. 1990, 112, 6004-6015.

(47) Mills, A.; McDiarmid, K.; McFarlane M.; Grosshans, P Chem. Commun. 2009,1345-1346.

(48) de Silva, A. P.; Gunaratne, H. Q. N.; Habib-Jiwan, J. -L.; McCoy, C. P.; Rice, T. E.; Soumillion, J. -P. Angew. Chem. Int. Ed. Engl. 1995, 34, 1728-1731.

(49) Tusa, J. K.; He, H. J. Mater. Chem. 2005, 15, 2640-2647.

(50) www.optimedical.com.

(51) Gan, J. A.; Chen, K. C.; Chang, C. P.; Tian, H. Dyes Pigm. 2003, 57, 21-28.

(52) Liu, B.; Tian, H. Chem. Commun. 2005, 3156-3158.

(53) Liu, T. Y.; Liu, X. G.; Spring, D. R.; Qian, X. H.; Cui, J. N.; Xu, Z. C. Sci. Rep. 2014, 4, 5418.

(54) Qian, X. H.; Xiao, Y.; Xu, Y. F.; Guo. X. F.; Qian, J. H.; Zhu, W. P. Chem. Commun. 2010, 6418-6436.

(55) Georgiev, N. I.; Dimov, S. M.; Asiri, A. M.; Alamry, K. A.; Obaid, A. Y.; Bojinov, V. B. J. Lumin. 2014, 149, 325-332

(56) Ludlow, R. F.; Otto, S. Chem. Soc. Rev. 2008, 37, 101108.

(57) de Silva, A. P.; Gunaratne, H. Q. N.; McCoy, C. P. Chem. Commun. 1996, 2399-2400.

(58) de Silva, A. P.; James, M. R.; McKinney, B. O. F.; Pears, D. A.; Weir, S. M. Nature Mater. 2006, 5, 787-790.

(59) Irie, M.; Fukaminato, T.; Sasaki, T.; Tamai, N.; Kawai, T. Nature 2002, 420, 759-760.

(60) Green, J. E.; Choi, J. W.; Boukai, A.; Bunimovich, Y Johnston-Halperin, E.; Delonno, E.; Luo, Y.; Sheriff, B. A.; Xu, K.; Shin, Y. S.; Tseng, H. R.; Stoddart, J. F.; Heath, J. R. Nature 2007, 445, 414-417. 


\section{Object Image}

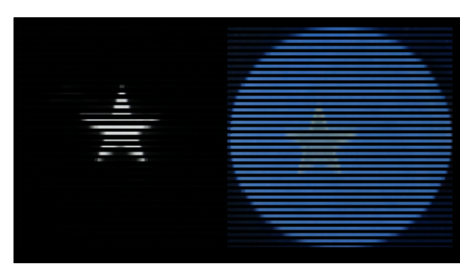

Table of Contents artwork 